\title{
NUEVAS OBRAS DE JENARO PÉREZ VILLAAMIL Y CARLOS DE HAES
}

La intención del presente trabajo es dar a conocer y catalogar algunas obras, aparecidas últimamente, de estos dos grandes maestros del paisajismo español del siglo XIX. Unas tienen el interés de aportarnos, o ampliarnos, la visión de una etapa determinada del artista de la que tenemos escaso conocimiento; otras meramente contribuyen a aumentar el catálogo conocido de las obras de estos pintores y, aunque nada nuevo aporten al juicio que de su pintura poseemos en general, ya eso mismo siempre resulta de por sí un valor añadido a su producción, y más si se trata de algún buen cuadro; y, por último, también tenemos el caso de la obra que ha podido ser identificada gracias a sernos conocido previamente su dibujo preparatorio.

Comenzaremos por las que nos amplían la visión de una etapa pictórica poco conocida del paisajista romántico español Jenaro Pérez Villaamil (El Ferrol, 1807-Madrid, 1854), haciendo referencia a cuatro obras especialmente interesantes por pertenecer a la que he denominado su etapa o década prerromántica ${ }^{1}$, que transcurre desde su llegada a Cádiz en 1823 (cuando comienza a formarse como pintor) y 1833, año en el que, a su vuelta de Puerto Rico, conoce en España al pintor escocés David Roberts (Stockbridge, Edimburgo, 1796-Londres, 1864), viajero a la sazón por nuestra tierra, lo que produce un cambio en su pintura hacia un paisajismo romántico fuertemente influenciado por el de este pintor británico. Realmente, el tipo de pintura que verdaderamente nos es familiar de Pérez Villaamil es el que realiza a partir de su contacto con Roberts en 1833; pero casi nada conocíamos pictóricamente de esos diez primeros años de profesión, que discurrieron entre 1823 y 1833, más que unas poquísimas obras a la acuarela que publicó, allá por los años treinta del siglo xx, Méndez Casal, quien también describió algún cuadro al óleo de esa primera década igualmente por él visto entonces ${ }^{2}$. Pero, desde hace unos años a esta parte, me han ido llegando, por diversos conductos, una serie de cuadros, firmados y fechados por Pérez Villaamil entre 1828 y 1830 unos, y otros que, aunque no lo estén, su idéntico estilo, temática y factura los hacían inconfundiblemente de esa etapa de nuestro artista. Con ellos, publicados por mí en diversos medios ${ }^{3}$, podemos conformar ya un pequeño catálogo que nos aporta una visión bastante aproximativa del tipo de pintura practicado por Pérez Villaamil en aquellos sus primeros años, y que nos permite valorar el cambio sufrido tras su conocimiento de David Roberts, respecto a su pintura anterior.

Muchas de estas obras están firmadas y fechadas, como hemos dicho, entre 1828 y 1830, siendo parte importante de ellas vistas de la ciudad y alrededores de Cádiz, cosa lógica ya que era donde residía el pintor por esos años antes de marchar en 1830 a Puerto Rico. Pues bien, Cádiz también es el tema de tres de los cuatro nuevos cuadros que traemos pertenecientes a esa década prerromántica de Pérez Villaamil, y los tres nos muestran vistas muy próximas del Castillo de San Sebastián y la desaparecida Puerta de las Caletas, estando todos firmados, y fechados dos de ellos en 1829. El idéntico estilo, factura y asunto del que no está fechado, hace que, indudablemente, lo datemos en la misma fecha, o muy próxima, de los anteriores.

El primero de ellos es el que titulamos por su clara temática Vista de la Puerta de las Caletas y Castillo de San Sebastián (Cádiz) (Fig. 1). Es un óleo sobre lienzo de $44 \times 57,5 \mathrm{cms}$, firmado y fechado en el ángulo inferior derecho, en la parte baja del muro: «G. P. de Villamil

\footnotetext{
1 Arias Anglés, E., «La década prerromántica del pintor Jenaro Pérez Villaamil», Estudios Pro Arte, núm. 6, 1976, p. 31; Arias Anglés, E., J. Pérez Villaamil, Ed. Atlántico, La Coruña, 1980, p. 51; Arias Anglés, E., El paisajista romántico Jenaro Pérez Villaamil, Madrid, CSIC, 1986, p. 174.

${ }^{2}$ Méndez Casal, A., «Unas acuarelas inéditas de la primera época de Villaamil», Revista Española de Arte, año I, núm. 1, marzo de 1932, p. 40.

3 Vid. obras citadas en nota anterior y además: Arias Anglés, E., «Jenaro Pérez Villaamil» en VV.AA., De la Edad Media al Romanticismo, Caylus, Madrid, 1993, p. 210; Arias Anglés, E., «Jenaro Pérez Villaamil» en VV.AA., Tres siglos de pintura, Caylus, Madrid, 1995, p. 246.
}

AEA, LXXVII, 2004, 306, pp. 171 a 201 


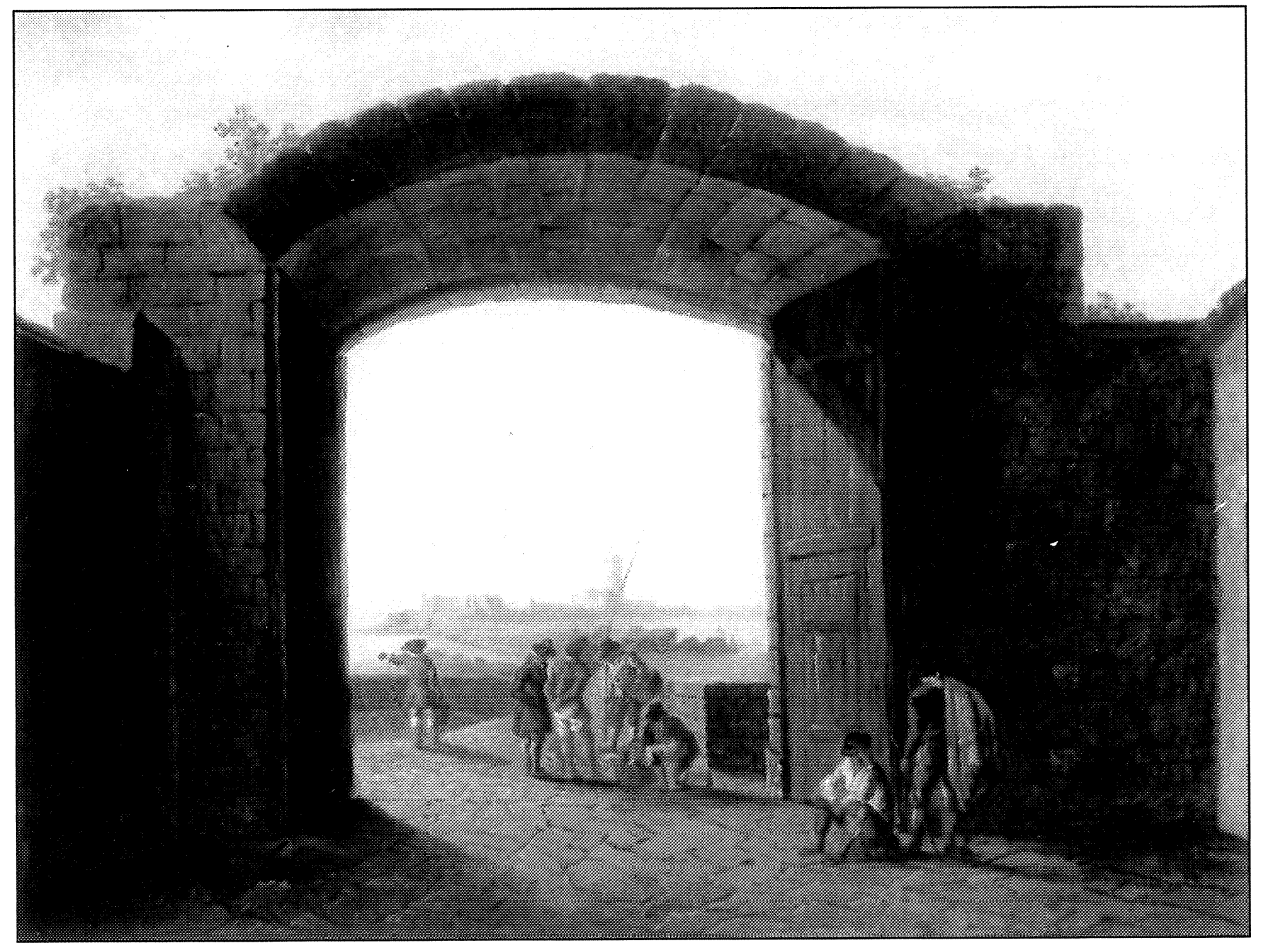

1

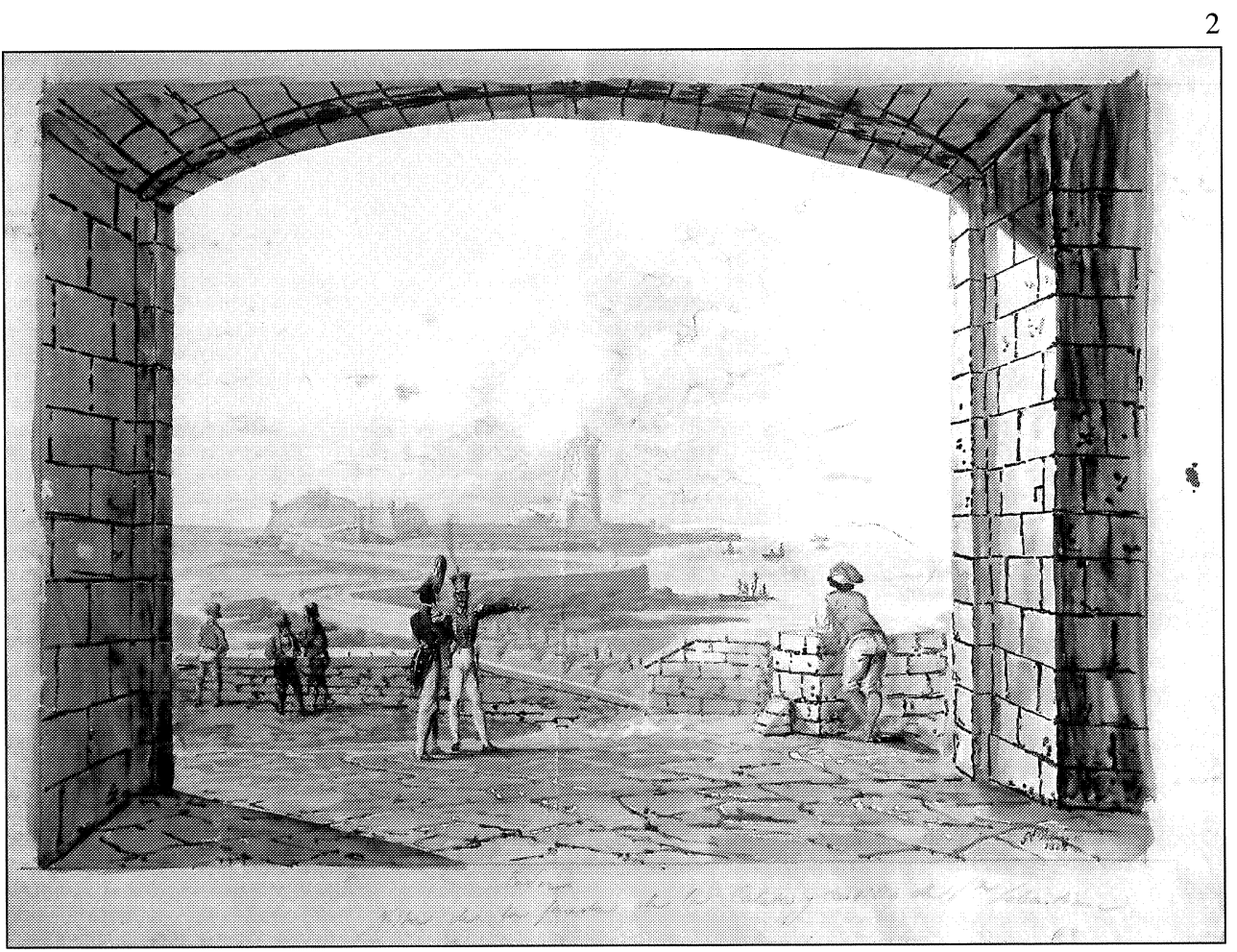

Fig. 1. Jenaro Pérez Villaamil. Vista de la Puerta de las Caletas y Castillo de San Sebastián (Cádiz). Óleo/ lienzo. Paradero desconocido.

Fig. 2. Vista de la Puerta de las Caletas y Castillo de San Sebastián (Cádiz). Dibujo a lápiz sobre papel. Paradero desconocido.

$A E A$, LXXVII, 2004, 306, pp. 171 a 201 


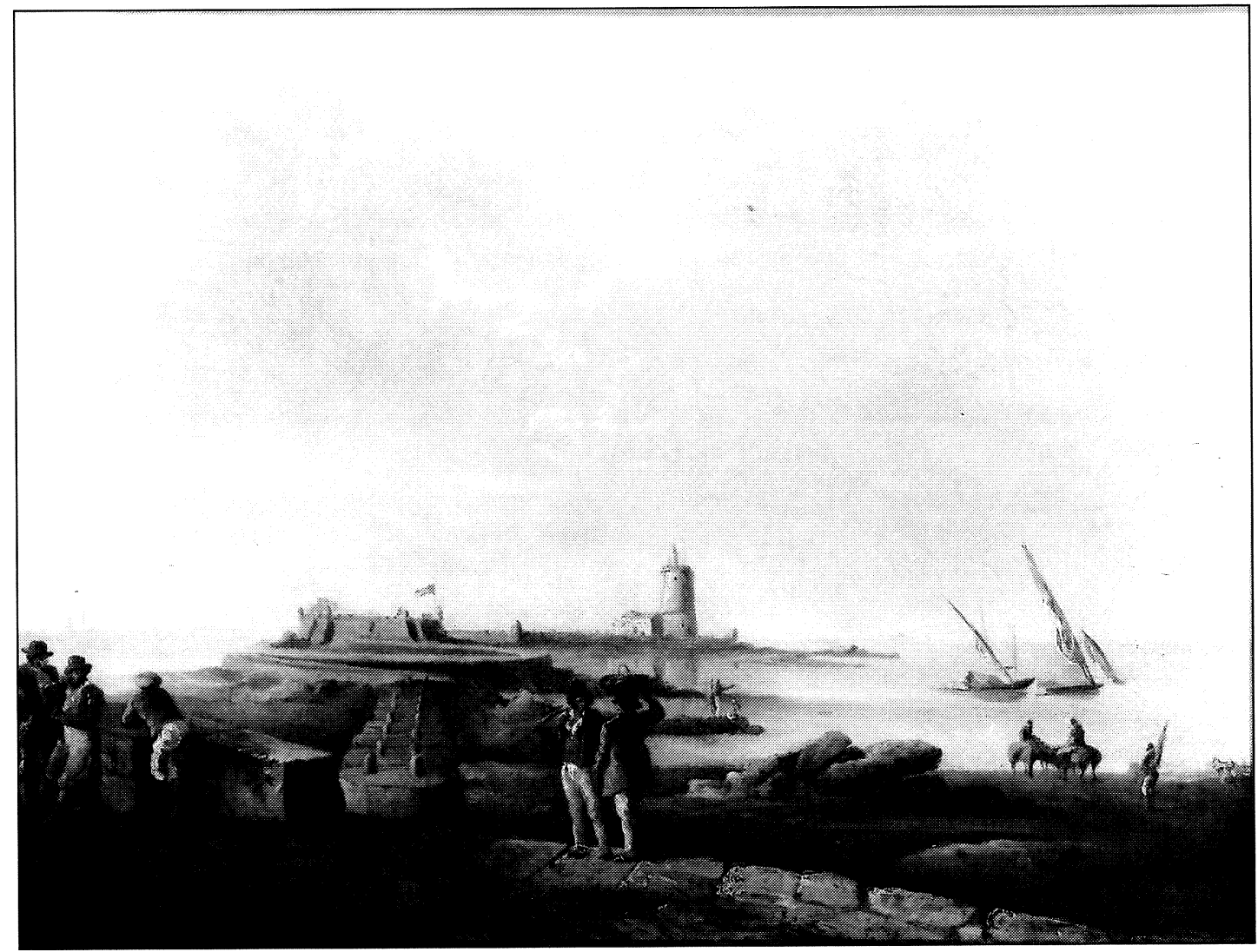

Fig. 3. Jenaro Pérez Villaamil. Vista del Castillo de San Sebastián desde el exterior de la Puerta de las Caletas. Óleo sobre papel montado en tela. En el comercio.

/ 1829». Apareció hará un par de años en el comercio de Madrid e imagino que ahora estará en alguna colección particular. Como todas estas obras primerizas de Pérez Villaamil, forma parte de un conjunto específico con especiales características dentro de su producción. Se trata de obras un tanto eclécticas, en general, que denotan unas veces el influjo de la pintura flamenca del siglo xvir y otras de la francesa del siglo xviII, especialmente de J. Pillement y C. J. Vernet ${ }^{4}$. Aunque muchas de ellas son de carácter fantástico o inspiradas en pinturas y grabados de estos y otros autores, Villaamil pintó también por estas fechas, durante sus años de permanencia en Cádiz (1823-1830), según hemos dicho, numerosas acuarelas y cuadros con vistas de dicha ciudad y sus alrededores, serie de obras a la que pertenece el cuadro que tratamos. Son vistas tomadas del natural con el aditamento de personajillos populares y soldados que le proporcionan el sabor local correspondiente. Por lo que conocemos, el influjo que muestran, en general, esta serie de vistas gaditanas, es el francés del siglo xvIII, pero diluido ya dentro de unas características muy personales del autor. Este último es el caso de la pintura que estudiamos, que nos muestra un suave influjo de la pintura francesa del siglo xviII, con especial recuerdo de las obras de C. J. Vernet, españolizado por medio de los personajes típicos andaluces que inscribe en la composición.

El hallarse firmado y fechado el cuadro en 1829 , nos lo sitúa perfectamente dentro de esa serie de vistas de Cádiz que realizó el artista durante su período de permanencia en dicha ciudad, que están casi todas ellas fechadas, como decimos, entre 1828 y 1830, año este último en

${ }^{4}$ Arias Anglés, E., op. cit., nota 1. 
que abandona Cádiz y marcha a Puerto Rico. De hecho, el mayor conjunto de estas obras de que se tiene noticias, las doce acuarelas con vistas gaditanas que pertenecían a la colección del duque de T'Serclaes en 1932, se hallaban todas fechadas en $1828^{5}$. Y decimos esto, además, porque conocemos la acuarela que, posiblemente, sirvió de base a este cuadro (Fig. 2), que fue publicada por mi hace unos años ${ }^{6}$, y que se halla firmada y fechada: «G. P. de Villamil 1828», coincidiendo con las que pertenecían al duque de T'Serclaes en 1932. La vista es la misma que la que nos presenta este cuadro que tratamos, sólo que tomada un poco más adentro de la Puerta de las Caletas y variando los personajillos populares que pueblan el conjunto. Existe, además, otra acuarela del artista, casi exactamente igual a ésta, con sólo alguna variación en los personajes, que pertenecía a la colección de Sarah L. Palacio en Buenos Aires ${ }^{7}$, que bien pudo ser también fuente de inspiración de este cuadro. Sea como fuere, una u otra acuarela, o ambas, fueron los estudios preparatorios para esta obra que tratamos.

La segunda de estas obras es de temática muy similar a la anterior, ya que se trata de una Vista del castillo de San Sebastián desde el exterior de la Puerta de las Caletas (Cádiz) (Fig. 3 ); es decir, la misma vista que en el cuadro anterior, pero tomada esta vez desde el exterior de dicha puerta en vez desde su interior. Es un óleo sobre papel montado encima de tela de $44,45 \times 57,78 \mathrm{cms}$, firmado en la parte inferior izquierda: «G. P. Villamil». Aunque no se halle fechado, este cuadro es de datación muy próxima al anterior por sus características estilísticas, factura y casi idéntica temática. Pero se da, además, el caso de que es pareja del cuadro que estudiamos a continuación que está fechado en 1829, ya que tiene también el mismo tipo de soporte (óleo sobre papel montado en tela), posee idénticas medidas que éste y es de la misma procedencia (se subastaron juntos en el comercio norteamericano), lo que nos proporciona la fecha de 1829 como la de realización de éste. Estilísticamente está en la misma línea que el anterior: claro influjo de la pintura francesa del siglo xvIII, con particulares recuerdos de C. J. Vernet y J. Pillement, pintores de tendencias claramente prerrománticas. Por ello, en estas obras están ya presentes componentes que caracterizarán su producción romántica posterior, como son el gusto por los amplios escenarios paisajísticos, la inclusión en ellos de arquitecturas y la presencia de personajillos populares poblando su espacio. Sin embargo, este influjo se diluye dentro de unas características muy personales del pintor, como se nos muestra de forma patente en estos cuadros que tratamos.

En esta serie de vistas gaditanas no es extraño encontrar dos o más versiones, ligeramente diferentes, de un mismo tema, en que normalmente nos presenta la visión de un idéntico monumento variando levemente el punto de vista, perspectiva y personajillos que lo adornan, como haría a menudo el pintor a lo largo de su vida. Tal sería el caso de este cuadro, en que la vista del Castillo de San Sebastián, desde la ya desaparecida Puerta de las Caletas, es asunto que plasmó cuatro veces, que sepamos. En tres de ellas el punto de visión está tomado desde el interior de dicha puerta, como en el primer cuadro antes analizado (Fig.1), la acuarela aparecida en el comercio de Madrid por mi publicada hace unos años (Fig. 2), o la que perteneció a la colección de Sarah L. Palacios ${ }^{8}$; a las que añadiríamos un óleo visto por mí en el comercio madrileño. En otra el punto de visión está tomado desde el exterior, como es el caso del cuadro que tratamos, por lo que la puerta no es aquí visible.

El tercero de estos cuadros que traemos de la década prerromántica de Pérez Villaamil, representa una Vista del malecón de Cádiz con el Castillo de San Sebastián al fondo (Fig.

\footnotetext{
5 Méndez Casal, A., op. cit., nota 2.

${ }^{6}$ Arias Anglés, E., J. Pérez Villaamil, Ed. Atlántico, La Coruña, 1980, p. 72, fig. 22.

${ }^{7}$ Larco, J. y Larraiza, M., La pintura española moderna y contemporánea, Madrid, 1964, vol. I, pp. 65 (reproducido) y 66 .

${ }^{8}$ Ibidem.
}

$A E A$, LXXVII, 2004, 306, pp. 171 a 201 


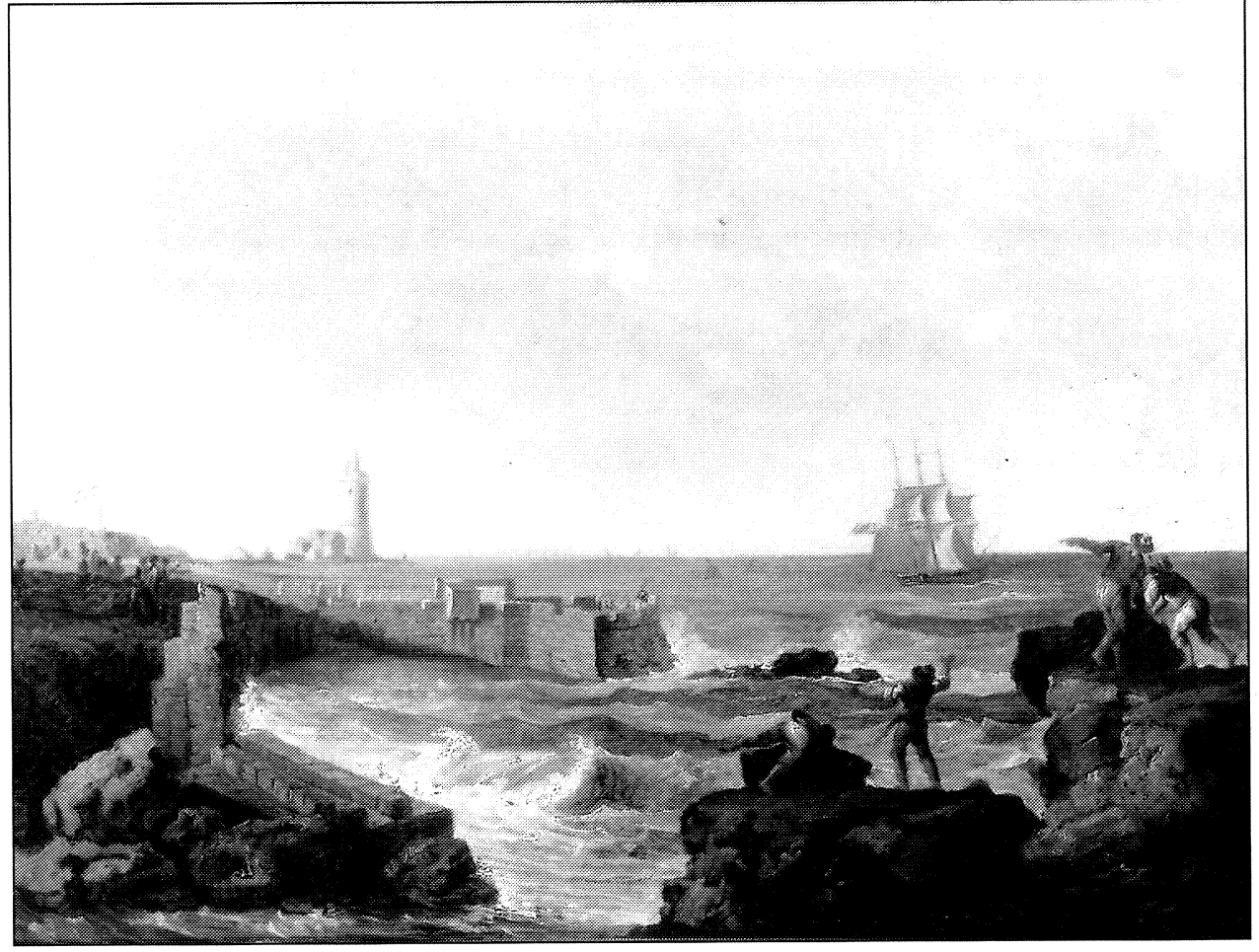

4

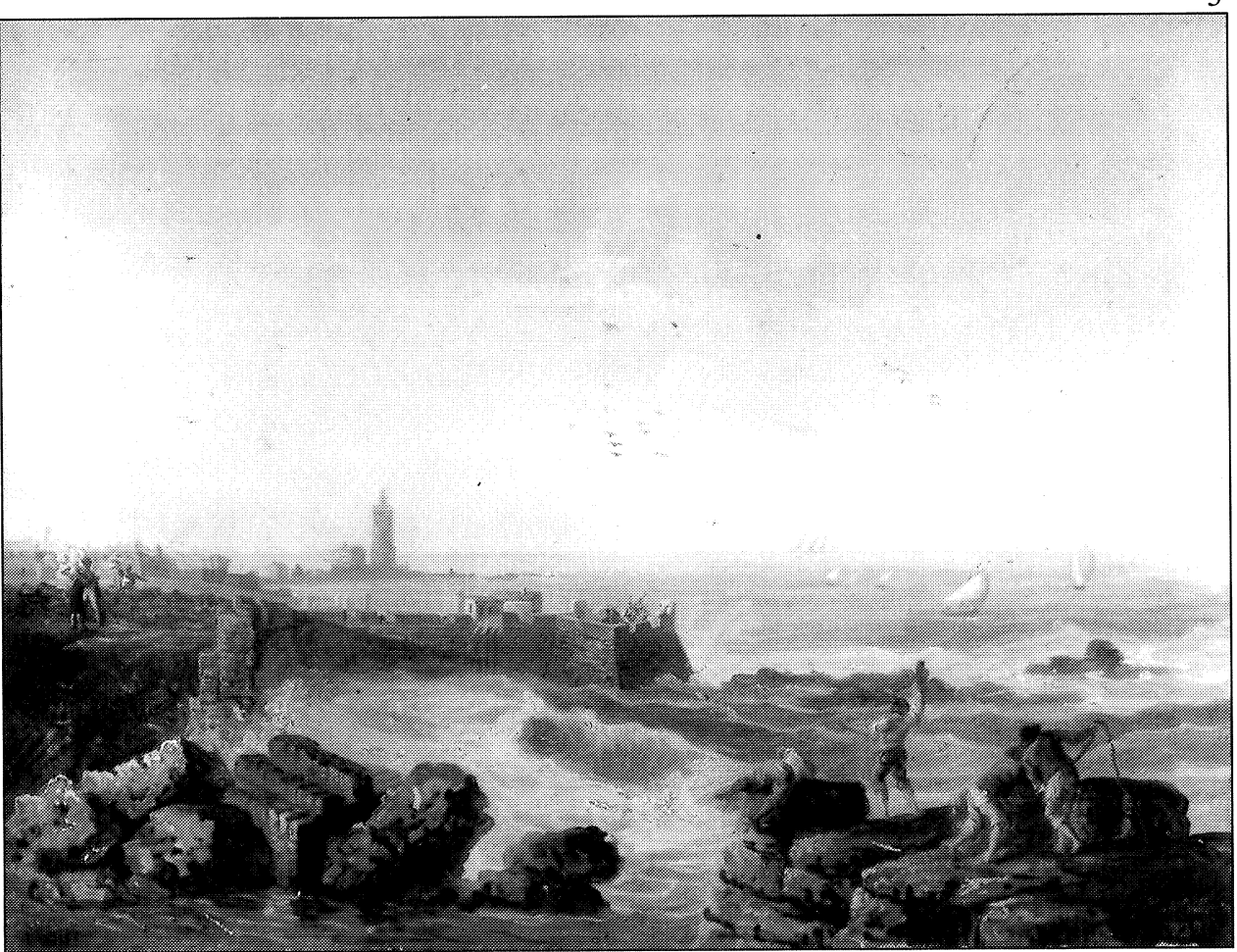

Fig. 4. Jenaro Pérez Villaamil. Vista del malecón de Cádiz con el castillo de San Sebatián al fondo. Óleo sobre papel montado en tela. En el comercio.

Fig. 5. Jenaro Pérez Villaamil. Vista del malecón de Cádiz con el castillo de San Sebastián al fondo. Óleo/ lienzo. Antigua colección Saldaña Suances (Barcelona).

$A E A$, LXXVII, 2004, 306, pp. 171 a 201 
4), y es, como decimos, pareja del anterior, junto al que fue subastado hace un par de años en el comercio norteamericano, procediendo ambos, lo más probablemente, de alguna colección de origen puertorriqueño o cubano. Es también un óleo sobre papel montado en tela, de idénticas dimensiones de 44,45 $\times 57,78 \mathrm{cms}$., firmado al centro izquierda, sobre las rocas de un murallón: «G. P. Villamil/1829». Pertenece, por tanto, también, como decimos, al núcleo más importante de la producción gaditana de estos años, las numerosas vistas de Cádiz que pintó entre 1828 y 1830. Estas vistas, que, como la presente, están firmadas por esos años, nos muestran claramente el influjo, como hemos dicho antes, de la pintura prerromántica francesa, y especialmente de Vernet. Así, este cuadro que tratamos entra plenamente dentro de esos parámetros: amplitud de visión panorámica, elementos arquitectónicos referenciales y personajillos populares aportando sabor local. El influjo de Vernet es patente en todo ello, y especialmente en las figuras del primer término a la derecha, que incluso parecen estar copiadas, por sus afectadas posturas, de algún repertorio de grabados de obras del pintor francés.

Ya en esta producción del final de su etapa gaditana, Villaamil, iniciando una constante que se repetirá luego a lo largo de su vida, como antes dijimos, reprodujo algunos de estos cuadros de vistas de Cádiz en una o varias versiones (según su éxito de venta o demanda de clientela). Así, conocemos la existencia de otro cuadro prácticamente igual al que nos ocupa, con ligeras variantes, y casi de idénticas dimensiones, firmado y fechado también en 1829 (Fig. 5), que pertenecía en los años setenta a la colección Saldaña Suances de Barcelona y que fue publicado por mí con el título de Vista de Cádiz ${ }^{9}$. El punto de visión es el mismo, pero denotando una perspectiva del faro y castillo de San Sebastián más alejada el de Barcelona, mientras que en el que tratamos se nos aproximan las lejanías con más claridad, desapareciendo también en el de Barcelona el navío de tres mástiles que aparece en la parte derecha de éste. Cual sea el original de los dos es imposible decirlo, pero lo que es indudable es que ambos son de Villaamil y que los pintó, casi simultáneamente, en el mismo año.

Aparte de estas vistas gaditanas, Pérez Villaamil realizó también, en esta su primera década, otras obras de carácter más o menos fantástico o imaginativo, generalmente sacadas de grabados de cuadros de pintores paisajistas prerrománticos franceses o flamencos del siglo XVII, y quizá en algún caso tomadas directamente de cuadros de esos pintores que llegase a conocer en colecciones gaditanas. Este es el caso del cuarto de los cuadros que analizamos pertenecientes a su primera etapa, al que por su temática titulamos Paisaje costero (Fig. 6). Se trata de un óleo sobre lienzo, de 47,5 × 66,7 cms., de colección particular gallega, que, aunque no se halla firmado, reúne, sin embargo, todas las peculiaridades estilísticas, técnicas y compositivas de otras obras conocidas de esta su primera etapa prerromántica, manifestándonos igualmente de forma clara el influjo de la pintura prerromántica francesa del siglo xvIII, y en especial de Vernet. Es obra, por tanto, que nos muestra netamente las características de este tipo de pintura, muy semejantes a las que posteriormente le transmitió a Pérez Villaamil su amigo David Roberts, y que son las que dominarán ya en toda su producción, con amplitud de visión panorámica y personajillos populares aportando sabor local. Además, este cuadro nos remite, concretamente, al Paisaje fantástico (Paisaje con río, castillo y escena de pescadores) del Museo de Pontevedra ${ }^{10}$, firmado y fechado en 1828 , y al también del mismo museo que titulamos Marina ${ }^{11}$, ambos concebidos por el artista asimismo bajo el influjo de la pintura de paisaje prerromántica francesa, y a los que claramente nos recuerda éste que estudiamos. La enor-

\footnotetext{
${ }^{9}$ Arias Anglés, E., El paisajista romántico Jenaro Pérez Villaamil, Madrid, CSIC, 1986, p. 205 , núm. 6, fig. 7.

${ }^{10}$ Ibidem, p. 203, núm. 1, lám. I, fig. 3.

11 Ibidem, p. 203, núm. 2; catálogo exposición Jenaro Pérez Villaamil (1807-1854), Fundación Caixa Galicia, MadridLa Coruña-Pontevedra, 1996, p. 37 (reproducido).
}

$A E A$, LXXVII, 2004, 306, pp. 171 a 201 


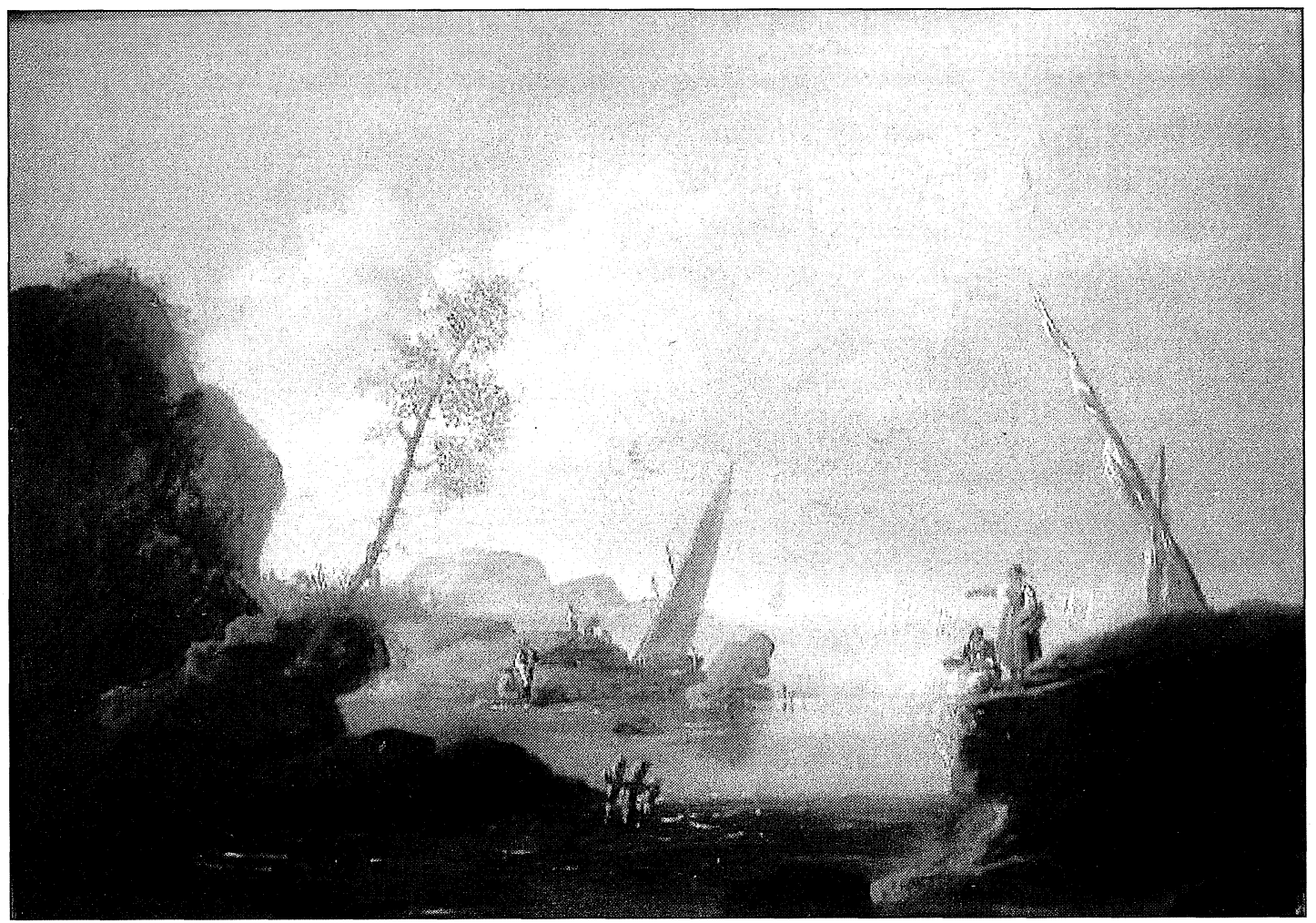

Fig. 6. Jenaro Pérez Villaamil. Paisaje costero. Óleo/lienzo. Colección particular gallega.

me similitud, en todos los órdenes, entre estos tres cuadros hace que, indudablemente, sea también obra de Pérez Villaamil este nuevo que traemos.

En efecto, no es sólo la semejanza en la composición, que además, al igual que en los otros del Museo de Pontevedra, es, en mayor o menor grado, de libre inspiración en los paisajistas prerrománticos franceses del siglo XviII; sino también la factura, con especial indicación en la similitud de los promontorios rocosos, coronados por el mismo tipo de vegetación en todos ellos y de igual modo de ejecución; así como también la forma de representar los árboles, en el cuadro que estudiamos y el Paisaje fantástico del Museo de Pontevedra, siendo en ambos casos del mismo tipo, semejante disposición e idéntica factura del follaje; igualmente nos remiten a los pinceles del artista, la suavidad de la luz, la finura de colorido, sus rosados fondos y la característica ejecución de los celajes y personajillos que pueblan la composición; todo ello, en fin, nos remite claramente a Pérez Villaamil. A medida que vamos conociendo mejor estas obras de su primera época, nos damos cuenta de su calidad y de su importancia en la evolución posterior del pintor.

Además de estas obras prerrománticas de Pérez Villaamil, traemos también un par de cuadros pertenecientes a su plena etapa romántica. Pero mientras el asunto de uno de ellos es muy representativo de lo que normalmente conceptuamos como la típica temática villaamilesca, el del otro, sin embargo, se sale de tales parámetros, aunque no deja por ello de ser obra de este pintor, como a continuación veremos.

Al primero podemos darle el genérico título de Interior de catedral gótica (Fig. 7), asunto, como sabemos, muy representativo en la producción romántica de Jenaro Pérez Villaamil. Se trata de un óleo sobre lienzo de $60 \times 42,5$ cms., aparecido en el mercado alicantino, que, aun- 


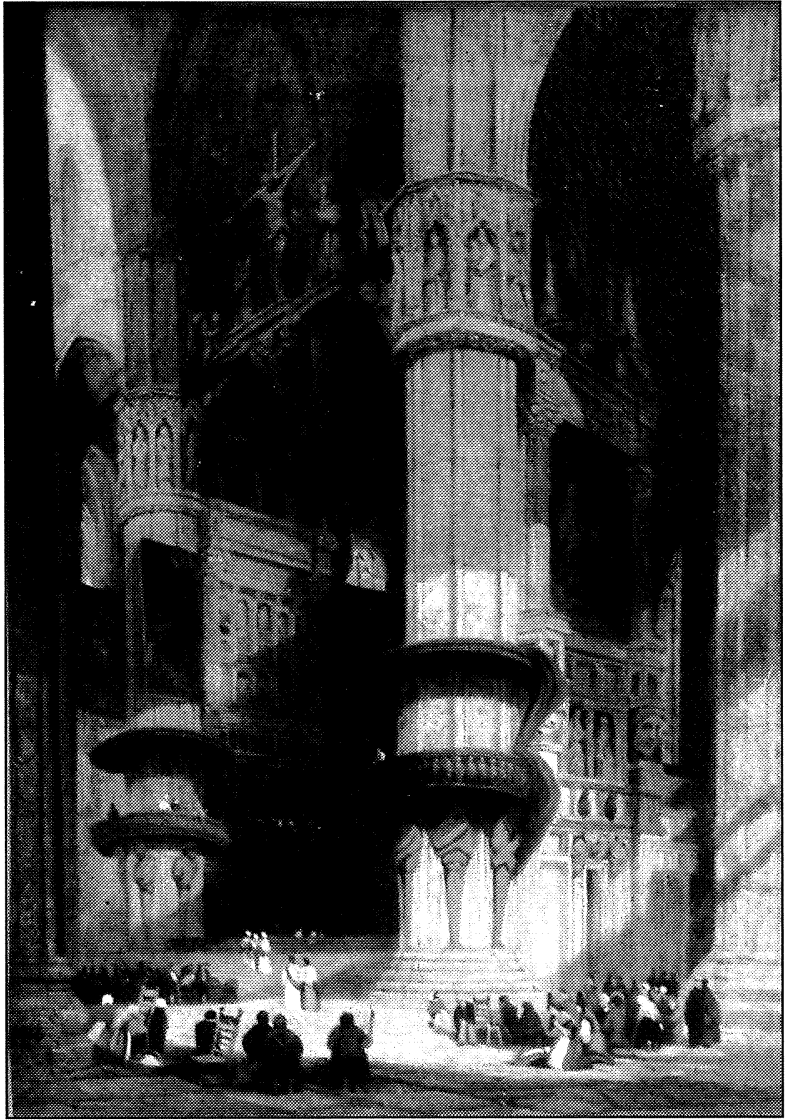

Fig. 7. Jenaro Pérez Villaamil. Interior de catedral gótica. Óleo/ lienzo. En el comercio.

que no está firmado, es obra de Jenaro Pérez Villaamil, reuniendo todas las características estilísticas, técnicas y de composición que definen su producción romántica.

Desde el punto de vista temático, se trata de un interior de catedral gótica con personajillos populares asistiendo a una ceremonia religiosa; asunto este que fue, como decimos, uno de los más significativos dentro de la copiosa producción de Pérez Villaamil, centrada principalmente en vistas exteriores de monumentos arquitectónicos en paisajes campestres y en panorámicas urbanas, así como en perspectivas de interiores de catedrales e iglesias, preferentemente medievales.

Para la realización de estas vistas interiores de templos, Pérez Villamil utiliza tres criterios. Unas están tomadas de la realidad, siendo representaciones, más o menos fidedignas, de algún edificio determinado; otras obedecen a una concepción puramente fantástica, sin ningún elemento tomado del natural, constituyendo creaciones nacidas de la pura imaginación del artista; y otras, en fin, son realizaciones fantaseadas, construidas mezclando diferentes elementos reales cogidos de diversos edificios que, combinados adecuadamente con el esquema arquitectónico básico de una catedral gótica, por ejemplo, nos reproducen la visión interior de un templo inexistente, aunque de cierto aspecto real; pero que, en conclusión, no dejan de ser este tipo de interiores creaciones nacidas también de la fantasía del artista.

A esta última categoría pertenece, sin duda, el cuadro que tratamos, que representa el fantástico interior de una catedral gótica, con enormes figuras antropomórficas adosadas a los pilares del crucero, por encima de sus bases; especie de cariátides o estípites que sostienen, a su vez, unos descomunales púlpitos circulares, al parecer de madera, que circundan todo el perímetro de dichos pilares a modo de balconadas, y desde los que se asoman algunos personajes; no menos fantásticas son las arquitecturas que se desarrollan tras los citados pilares, tanto en su estructura como en sus adornos, pero en las que hay una cierta base de elementos reales combinados y cambiados por el pintor a su antojo.

La técnica responde también a la empleada por Pérez Villaamil en este tipo de composiciones: Un colorido cálido, con una luminosidad que destaca los tonos dorados, conformando una atmósfera como de ensueño, que se pierde en penumbras algo misteriosas hacia el interior. Igualmente son muy características en este tipo de representaciones del artista gallego las filigranas, como de labor de encaje, que efectúa con la pasta pictórica para realizar y resaltar los adornos escultóricos que acompañan a los elementos arquitectónicos, patentes sobre todo en las esculturas bajo arquillos góticos que rodean, a modo de anillos, la parte superior de los

AEA, LXXVII, 2004, 306, pp. 171 a 201 
pilares del crucero. Y, por último, son también muy característicos del pintor los inconfundibles personajillos populares que pueblan el ámbito de la composición, muy representativos de su pintura, estando patentes en casi todas sus obras, y especialmente en las de este tipo, realizados normalmente con abundante empaste pictórico y toques de color calido.

El otro cuadro, aparecido en el comercio madrileño, se distancia algo, como hemos dicho, de lo que tópicamente conceptuamos como de temática villaamilesca. En efecto, una ejecución pública a «garrote vil» no es un asunto que nos remita mucho a la temática de Pérez Villaamil. Pero, aunque no esté firmado, sin embargo, es obra de nuestro artista. No sólo por su estilo y factura, que responden plenamente a la de nuestro pintor, sino porque además conocemos el dibujo preparatorio para el cuadro, donde, gracias a las inscripciones allí hechas de puño y letra del artista, sabemos dónde se realizó la ejecución, el día, mes, y hora, y el nombre del ajusticiado. De aquí que podamos darle el exacto título de Ejecución del facineroso Labrado (Fig. 8 ). Se trata de un óleo sobre lienzo de $41,5 \times 55,5 \mathrm{cms}$. que, aunque no está firmado, como decimos, reúne todas las características técnicas y estililísticas de la etapa romántica de Pérez Villaamil.

La composición diagonal del paisaje con las arquitecturas en la parte alta derecha del mismo, rozando casi la parte superior del cuadro, descendiendo hacia la izquierda para dejar un trozo de celaje y un huidizo y brumoso paisaje de lejanías, es algo característico en muchas de sus obras. Igualmente lo son los rosados celajes y su reflejo en las arquitecturas del fondo, así como el cálido colorido, de tonos ocres dorados en general salpicados de rojos, azules y blancos. Así mismo lo es la construcción tan inconfundible de los personajes, con esa técnica deshecha y manchista con resaltes del color, a modo de churrillos, sobre todo en los tonos claros; personajes que, en el caso del arriero con manta al hombro y las dos mujeres del pueblo que se hallan a su lado, en el ángulo inferior izquierdo del cuadro, hemos visto, sin duda, en otras de sus composiciones.

Pero no sólo son su técnica y estilo los que nos lo confirman como obra de Pérez Villaamil, sino que además, como hemos apuntado más arriba, conocemos el dibujo preparatorio para este cuadro, mencionado con el título de Una ejecución por garrote vil por Gaya Nuño ${ }^{12}$, y publicado posteriormente por mí con el mismo título que ahora le damos al cuadro aparecido ${ }^{13}$. Se trata de un dibujo a lápiz sobre papel, que fue expuesto en 1954 en la Exposición conmemorativa del centenario de su muerte en el Museo Romántico de Madrid, perteneciendo entonces a la colección Victorino Simón (Fig. 9). La escena que representa este dibujo es prácticamente idéntica a la del cuadro que tratamos, con las ligeras variantes que introdujo el pintor a la hora de reproducir el dibujo en el lienzo, como fueron la supresión de algún personajillo, para clarificar la composición, la variación de posturas de otros de dichos personajes o la introducción del perro a primer término del cuadro, para subrayar lo prosaico y cotidiano en medio de tan truculenta escena, como elemento distanciador. Además, dicho dibujo nos sirve para identificar el asunto que nos representa el cuadro, ya que, en la parte baja derecha del mismo, hay una inscripción autógrafa del artista que nos narra de forma escueta pero precisa de qué se trata: «27 de Octubre de 1838. En Madrid - á las 12 y 1/2 de la mañana - Ejecución del facineroso llamado Labrado». Con lo que nos enteramos de que se trata de una ejecución por garrote vil de la que fue testigo el artista, tomada de la realidad en aquél preciso y trágico

\footnotetext{
${ }^{12}$ Gaya Nuño, J. A., «Actualidad y centenario de Villaamil», Ínsula, núm. 104, agosto de 1954, p. 8; Gaya Nuño, «Crónica. Vida de los museos españoles durante el año de 1954. Museo Romántico», Boletín de la Sociedad Española de Excursiones, LVIII, 1954, p. 183.

${ }_{13}$ Arias Anglés, E., «Noticias inéditas en torno a una exposición de Villaamil», Archivo Español de Arte, t. XLV, núm. 179, julio-septiembre 1972, pp. 302-304, lám. III, fig. 1; Arias Anglés, E., El paisajista romántico Jenaro Pérez Villaamil, CSIC, Madrid, 1986, p. 343, núm. 475, fig. 174.
}

$A E A$, LXXVII, 2004, 306, pp. 171 a 201 


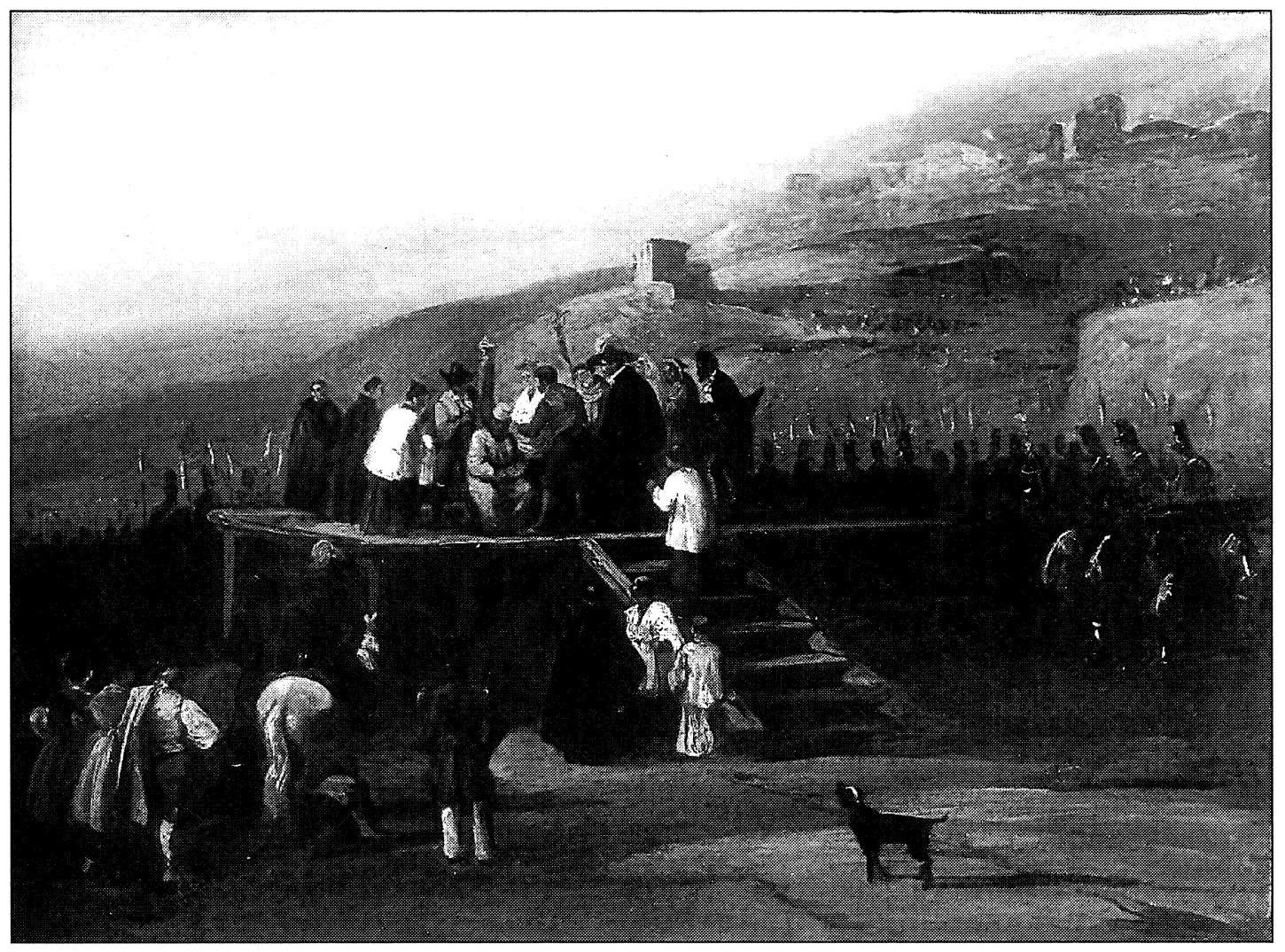

8

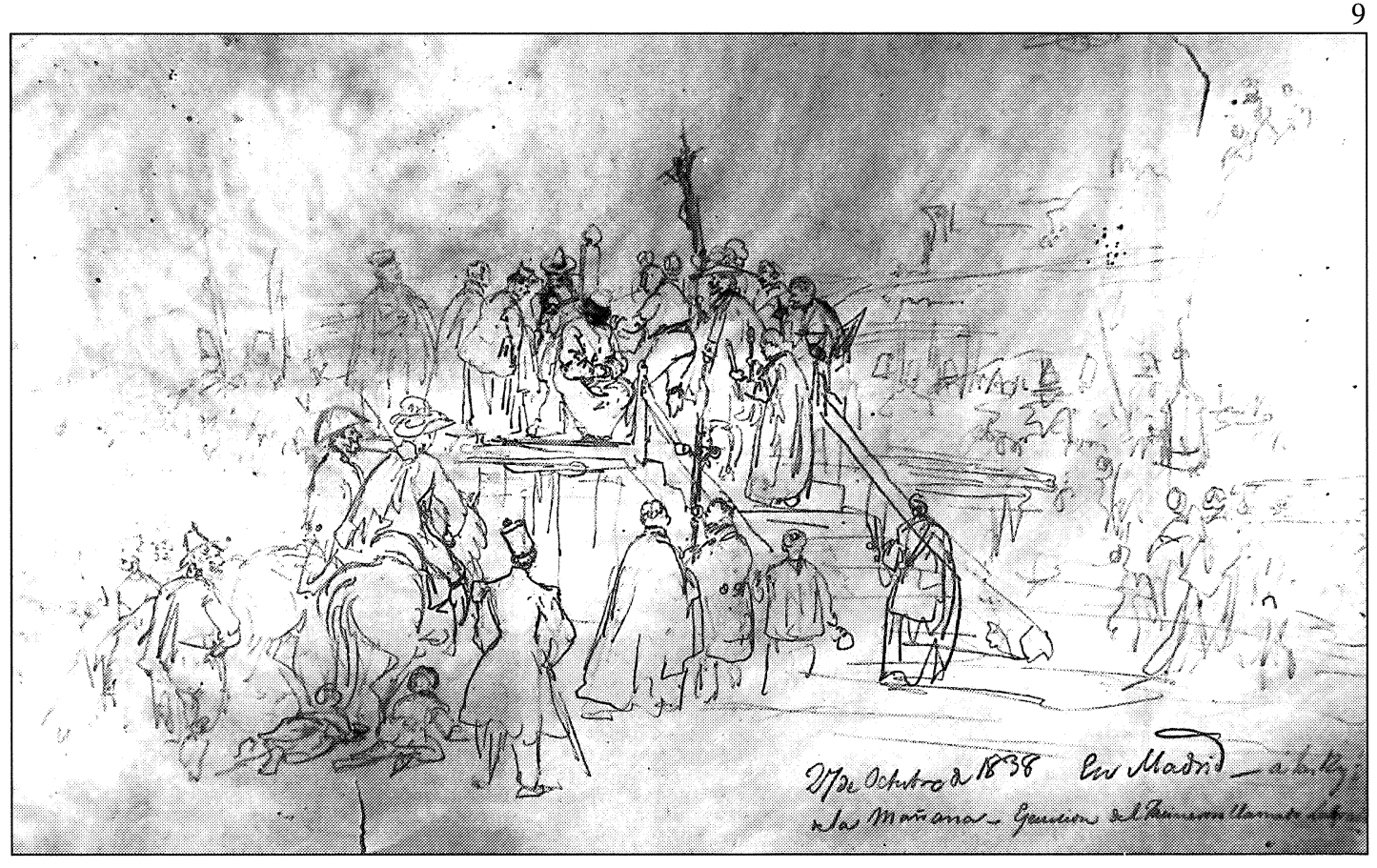

Fig. 8. Jenaro Pérez Villaamil. Ejecución del facineroso Labrado. Óleo/lienzo. En el comercio.

Fig. 9. Jenaro Pérez Villaamil. Ejecución del facineroso Labrado. Dibujo a lápiz sobre papel. Antigua colección Victorino Simón (Madrid).

AEA, LXXVII, 2004, 306, pp. 171 a 201 
momento, mediante un apunte a lápiz del natural, así como también del nombre del ejecutado, lugar de la ejecución y del año, mes, día y hora exacta del acontecimiento.

Analizadas las correspondientes obras del romántico Pérez Villaamil, pasemos ahora a hacerlo con los tres nuevos cuadros aparecidos del gran paisajista del naturalismo español Carlos de Haes (Bruselas, 1826-Madrid, 1898).

Los dos primeros son pareja, sin duda, ya que tienen la misma procedencia, técnica, soporte, dimensiones e, incluso, idéntico marco. Uno de ellos, el que titulamos Paisaje montañoso con río (Fig. 10), es un óleo sobre lienzo, de $49 \times 73 \mathrm{cms}$., firmado en el ángulo inferior izquierdo «C. de Haes». Nos representa, en un tipo de composición bastante repetida por Haes en estos asuntos de alta montaña, un riachuelo torrencial que, procedente del fondo - donde se eleva un alto pico montañoso nevado-, discurre espumeante hasta el primer término del cuadro, dividiendo así la composición en dos partes y conduciendo nuestra mirada hacia la montaña; el cielo es nuboso y plomizo, pero la atmósfera es clara y la visión definida. Igualmente el otro cuadro, que titulamos Paisaje montañoso con laguna (Fig. 11), es también un óleo sobre lienzo, de $49 \times 73 \mathrm{cms}$., firmado asimismo en el ángulo inferior izquierdo «C. de Haes». Enormemente semejante al anterior tanto en estilo como en técnica (lo que nos indica su común realización por las mismas fechas), nos representa también un paisaje de estructura algo similar al otro, dominando también los fondos un picacho montañoso nevado, pero de concepción más serena, subrayada por la placidez de las aguas de la laguna que llegan hasta los primeros términos del cuadro y la atmósfera ligeramente brumosa, que un cielo azul y de escasas nubes tiñe de un suave tono dorado. Se trata, pues, de dos bellos paisajes de alta montaña que, además de estar firmados, muestran claramente todas las características estilísticas y técnicas representativas de sus obras de segunda etapa. Y es por esta razón, por poner de manifiesto ambos las mismas características, por lo que los analizaremos conjuntamente.

El representar los dos cuadros asuntos de alta montaña y, al parecer, vistas posiblemente de la misma cordillera, nos permite precisar, en líneas generales, su posible fecha de realización, ya que Haes comenzó a entrar en contacto con este tipo de asuntos en 1872, cuando fue a pintar durante el verano a Santander y Vizcaya, descubriendo entonces los paisajes del norte de España, que fueron tan de su gusto, por ser tan semejantes en climatología y atmósfera a los de su tierra natal a que estaba tan acostumbrado ${ }^{14}$. Posteriormente, en 1874, viajó a Asturias, acompañado por sus discípulos Aureliano de Beruete y José Entrala, entrando ya, en esta ocasión, abiertamente en su temática los paisajes de alta montaña, plasmando repetidamente en sus lienzos la belleza de los Picos de Europa ${ }^{15}$. En ese mismo año de 1874, también en compañía de Beruete, pinta en Vascongadas y Navarra; campaña pictórica ésta que volvió a repetir en $1875^{16}$.

Vemos, pues, que el descubrimiento de los asuntos de alta montaña por parte de Haes, y la plasmación de los mismos en su pintura, se inscriben, basicamente, en el período comprendido entre 1872 y 1875 , pudiendo concretarse aún más el despertar de dicho interés en el año 1874, cuando comienzan a entrar ya abiertamente estos asuntos en su temática, quizá por sugerencia de Beruete ${ }^{17}$. Es pues dentro de este período que discurre entre 1872 y 1875 , en el que podemos fechar estos cuadros y, todavía más concretamente, entre 1874 y 1875, años en los que descubre los Picos de Europa y los Pirineos, pues se trata, sin duda de vistas de alguna de estas dos cordilleras.

\footnotetext{
${ }^{14}$ Pena, M. C., El paisaje español del xIx: del naturalismo al impresionismo, Universidad Complutense, Madrid, 1982, p. 195.

${ }^{15}$ Ibidem, p. 198.

${ }^{16}$ Ibidem, p. 199.

${ }^{17}$ Ibidem, p. 198.
}

$A E A$, LXXVII, 2004, 306, pp. 171 a 201 


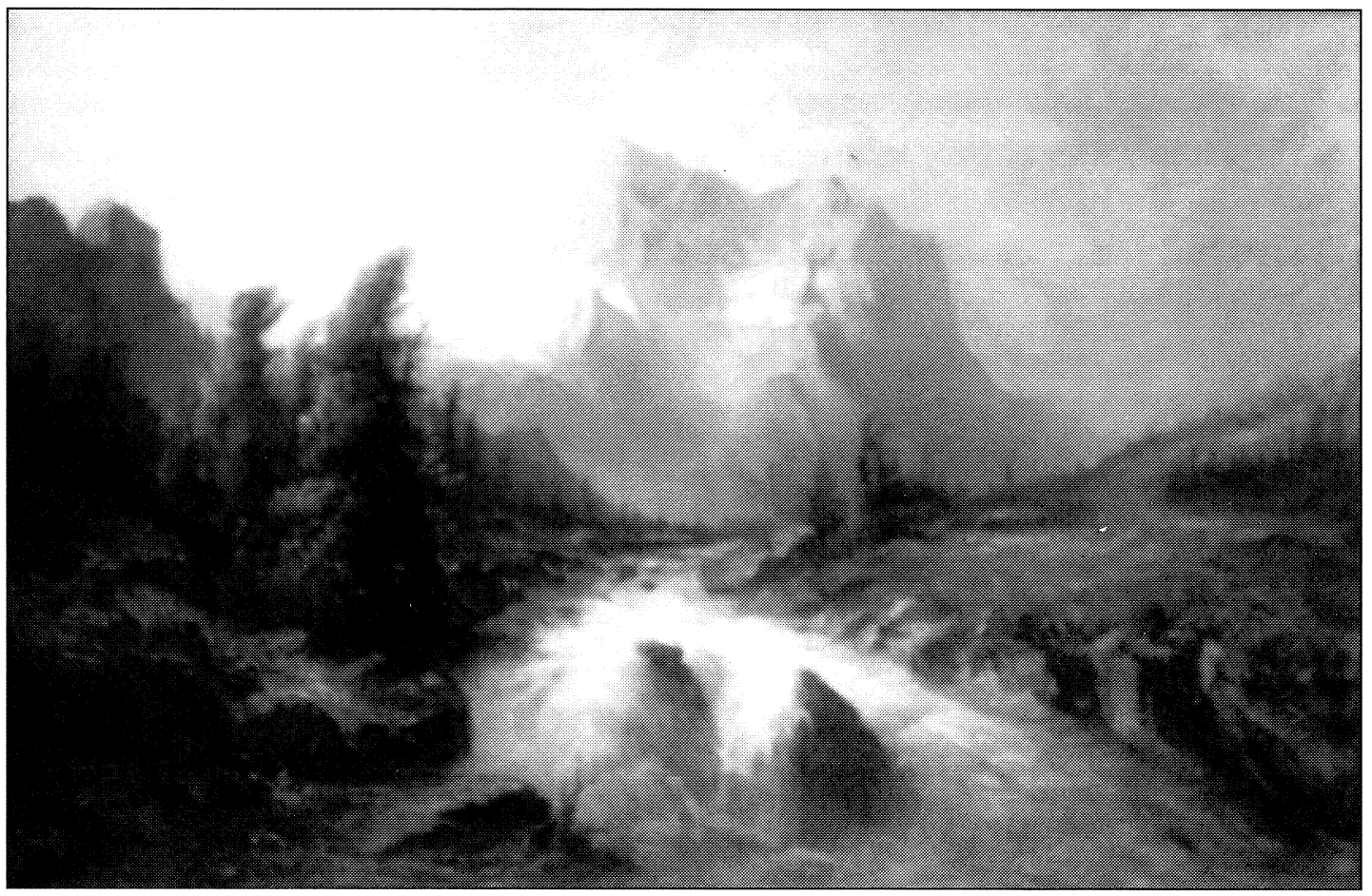

10

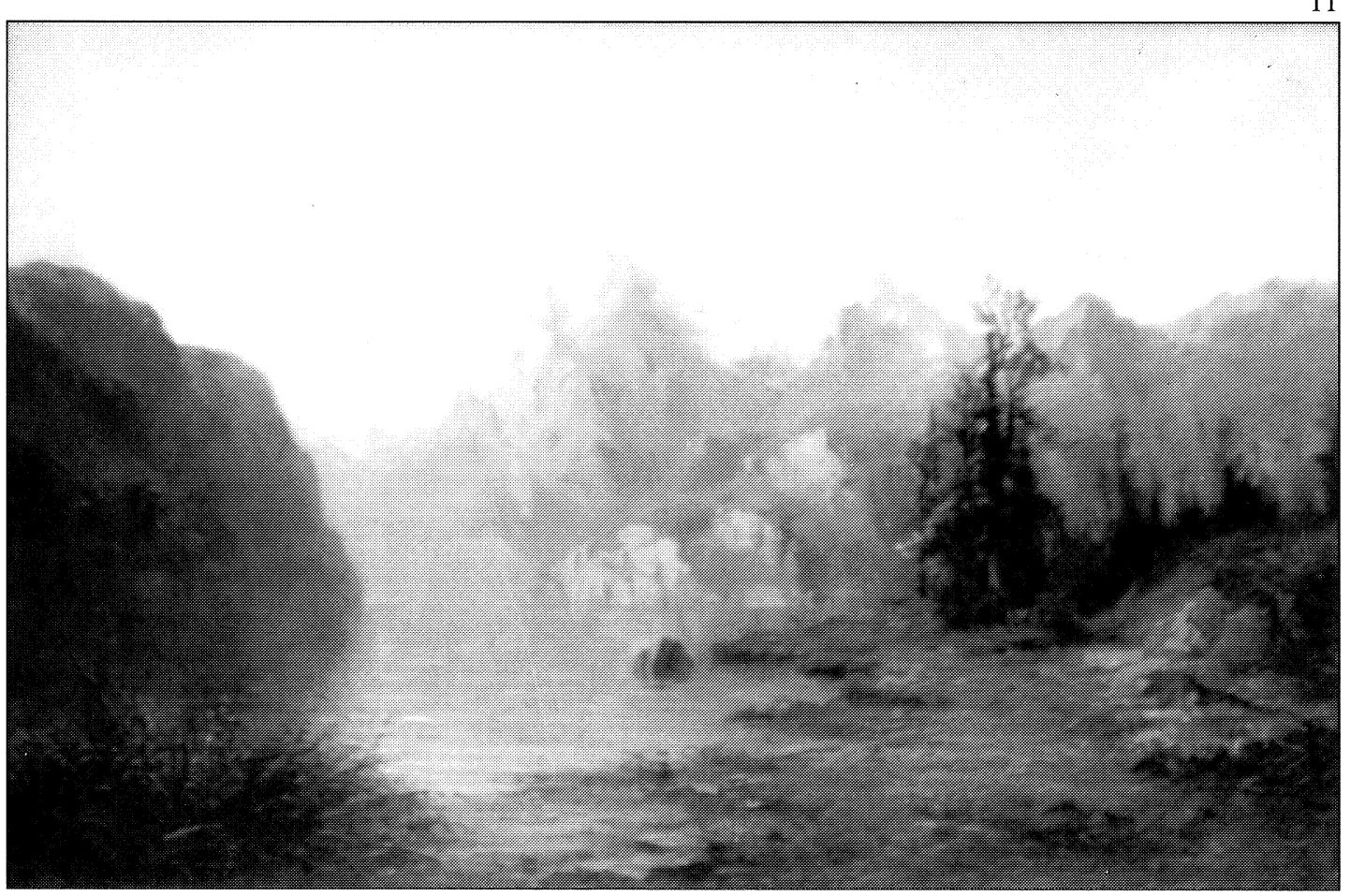

Fig. 10. Carlos de Haes. Paisaje montañoso con río. Óleo/lienzo. En el comercio.

Fig. 11. Carlos de Haes. Paisaje montañoso con laguna. Óleo/lienzo. Colección particular (Alicante).

AEA, LXXVII, 2004, 306, pp. 171 a 201 


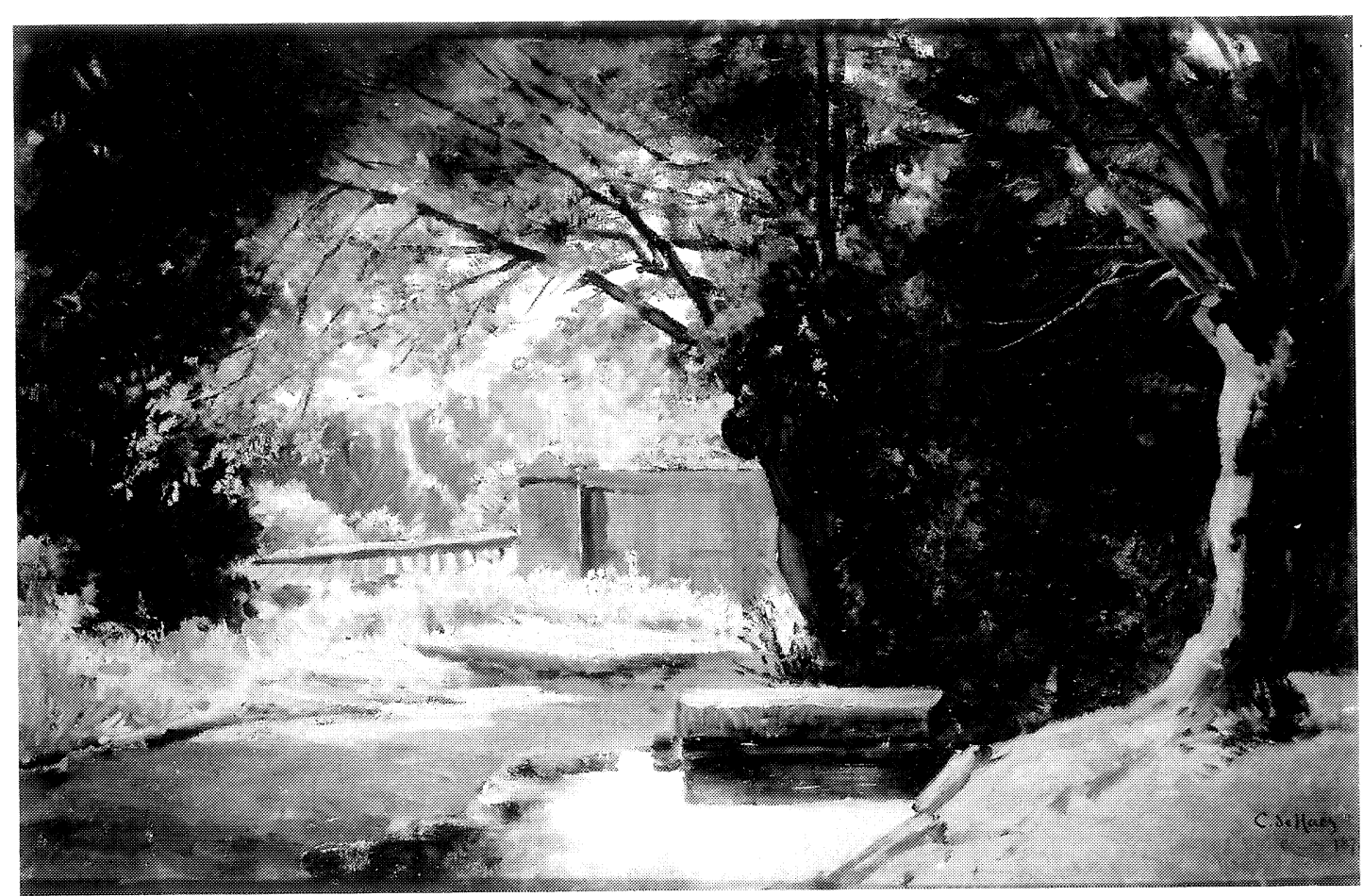

Fig. 12. Carlos de Haes. Paisaje con tapia. Óleo/lienzo. Colección particular (Madrid).

Además de ello, por su técnica, composición y colorido parecen pertenecer a la que Cid Priego ${ }^{18}$ denominó como su segunda etapa, fechable, según dicho autor, entre 1870 y 1880 , y que se caracteriza por un aclaramiento de su paleta y, como consecuencia, por un colorido más alegre y brillante que el de su primera etapa, eliminando los asfaltos y los tonos terrosos, así como la dureza dibujística anterior y pintando con mayor desenvoltura; es decir, son obras las de esta segunda etapa realizadas, en general, con un colorido más jugoso y una factura mas suelta, como es el caso de las obras que tratamos.

Así, pues, existe una perfecta coincidencia, en cuanto a la posible fecha de realización de estos cuadros, tanto en el aspecto estilístico de las obras como en su temática; pues según su estilo estarían realizados entre 1870-1880, pudiendo concretarse aún más, respecto a los asuntos de alta montaña que nos muestran, entre 1874 y 1875.

Ambos cuadros poseen una suelta y espontánea factura y un muy natural tratamiento lumínico, lo que, unido a sus relativamente cortas dimensiones, nos puede llevar a pensar que fuesen realizados directamente del natural. Pero si los comparamos con el tercero de los cuadros de Haes que traemos, y que a continuación analizamos, estos dos nos resultan mucho más acabados frente al acusado aspecto abocetado de este último. Por ello pensamos que, sin descartar totalmente que fuesen realizados directamente del natural por el artista, quizá los pintara en sesiones in situ lo suficientemente dilatadas como para dejarlos bastante acabados y, posteriormente, terminara de retocarlos en su taller. Es decir, que no se trata, en nuestra opinión, íntegramente de obras posteriores de taller, compuestas en él sobre algún boceto tomado de la realidad; lo que también nos indica y apoya que los realizase en las fechas ya indicadas.

Pero, desde luego, del que no existe ninguna duda sobre su directa realización del natural,

${ }_{18}$ Cid Priego, C., Aportaciones para una monografía del pintor Carlos de Haes, Instituto de Estudios Ilerdenses (CSIC), Lérida, 1956, pp. 18, 21 y 22.

$A E A$, LXXVII, 2004, 306, pp. 171 a 201 
por parte del artista, es del último de estos tres cuadros de Haes que estamos analizando, al que, como ocurre con otros muchos cuadros de este pintor a los que no se puede identificar su asunto, nos vemos obligados a darle el, a la vez simple y algo descriptivo, título de Paisaje con tapia (Fig. 12), por ser este elemento el único algo significativo de la composición. Se trata de un óleo sobre lienzo, de $37 \times 60 \mathrm{cms}$, que se halla firmado y fechado, en el ángulo inferior derecho, «C. de Haes / 1878».

En efecto, sus pequeñas dimensiones, su frescura de tratamiento, con esa espontánea y suelta factura, realizada a base de rápidos toques de pincelada y empaste de masas de color, así como el real y franco estudio de la impresión lumínica, su claro aspecto abocetado en una palabra, todo ello nos habla de su indudable realización directamente del natural, de que se trata, pues, de una ejecución in situ en una sola sesión frente a la naturaleza. O sea, que es ésta una de esas obras de Haes cargadas de la espontaneidad y frescura que sólo su enfrentamiento directo con la naturaleza les puede proporcionar, frente al realismo más acabado y académico presente en sus obras realizadas en el taller. De ello nos habla también claramente la simplicidad y sencillez de su asunto: un anónimo trozo de naturaleza, elegido, sin duda, por el artista en función de un efecto lumínico que le llamó la atención, producido por el verde y cargado ramaje de unos árboles en un paraje boscoso, del que tan sólo un camino y una tapia nos aportan una referencia humana. Se trata pues del estudio del efecto de plena luz sobre estos elementos arquitectónicos y el bosque que se desarrolla tras de ellos, junto con el más tamizado de los ramajes de la umbría del primer término, desde donde está tomada la vista, que actúan a modo de pantalla traslúcida. Este juego de contrastes es, como en otros muchos cuadros de este tipo de Haes, el sencillo pero natural, jugoso y espontáneo, asunto del cuadro.

Aunque conocemos su fecha de realización - la de 1878, puesta por el pintor junto a la firma-, aún en el caso de que no la supiéramos, indudablemente, por su propio estilo, técnica y colorido, sería clasificable en la segunda de las tres etapas en que Cid Priego ${ }^{19}$ divide, como antes dijimos, la producción de Carlos de Haes. Esta etapa sería, pues, la que discurre, según dicho autor, entre 1870 y 1880 , y que se caracteriza estilísticamente, según ya apuntamos, por la eliminación de los asfaltos y tonos obscuros y terrosos, así como la dureza dibujística, que dominaron en su primera etapa; distinguiéndose esta segunda por un mayor aclaramiento de su paleta, lo que se traduce ahora en la utilización de un colorido más alegre y de mayor brillantez que el de su primera etapa, a la par que utiliza también una técnica de mayor desenvoltura; o sea, que son obras las de esta segunda etapa realizadas, en general, con un colorido más jugoso y una factura más suelta, como podemos ver en esta obra que tratamos. Es decir, que existe, en este caso, una perfecta sincronía entre la fecha de realización y el estilo del cuadro.

ENRIQUe ARIAS ANGLÉs

CSIC

19 Ibidem.

$A E A$, LXXVII, 2004, 306, pp. 171 a 201 